\title{
Psychosocial predictors of nonadherence to medical management among patients on maintenance dialysis
}

This article was published in the following Dove Press journal: International Journal of Nephrology and Renovascular Disease 31 October 2016

Number of times this article has been viewed

\author{
Fahad Dakheel Alosaimi' \\ Mohammed Asiri² \\ Saleh Alsuwayt ${ }^{2}$ \\ Tariq Alotaibi ${ }^{2}$ \\ Mohammed Bin Mugren ${ }^{2}$ \\ Abdulmalik Almufarrih ${ }^{2}$ \\ Saad Almodameg ${ }^{2}$ \\ 'Department of Psychiatry, King \\ Saud University, Riyadh, Saudi Arabia; \\ ${ }^{2}$ College of Medicine, King Saud \\ University, Riyadh, Saudi Arabia
}

Background: A number of reports suggest a link between depression and nonadherence to recommended management for end-stage renal disease (ESRD) patients on maintenance dialysis. However, the relationship between nonadherence and other psychosocial factors have been inadequately examined.

Objectives: To examine the prevalence of psychosocial factors including depression, anxiety, insecure attachment style, as well as cognitive impairment and their associations with adherence to recommended management of ESRD.

Methods: A cross-sectional observational study was carried out from 2014 to 2015. Chronic dialysis patients were recruited conveniently from four major dialysis units in Riyadh, Saudi Arabia. Nonadherence was defined as decreased attendance in dialysis sessions, failure to take prescribed medications, and/or follow food/fluid restrictions and exercise recommendations.

Results: A total of 234 patients ( 147 males and 87 females) were included in this analysis, with 45 patients $(19.2 \%$ ) considered as nonadherent (visual analog scale $<8$ ). Approximately $17.9 \%$ of the patients had depression (Patient Health Questionnaire score $\geq 10$ ), $13.2 \%$ had anxiety (Hospital Anxiety and Depression scale-anxiety $>7$ ), while $77.4 \%$ had cognitive impairment (Montreal Cognitive Assessment score <26). Nonadherence was significantly associated with depression and anxiety ( $p<0.001$ for both) but not cognitive impairment $(p=0.266)$. The Experiences in Close Relationships - Modified 16 (ECR-M16) scale score was 27.99 \pm 10.87 for insecure anxiety and $21.71 \pm 9.06$ for insecure avoidance relationship, with nonadherence significantly associated with anxiety $(p=0.001)$ but not avoidance $(p=0.400)$.

Conclusion: Nonadherence to different aspects of ESRD continues to be a serious problem among dialysis patients, and it is closely linked to depression and anxiety. The findings from this study reemphasize the importance of early detection and management of psychosocial ailments in these patients.

Keywords: dialysis, nonadherence, depression, anxiety, Saudi Arabia

\section{Introduction}

End-stage renal disease (ESRD) has emerged as a major public health problem, with an alarming increase in incidences and a challenge for both developing and developed countries. ${ }^{1}$ Globally, it is estimated that 1.9 million patients are currently receiving renal replacement therapy (RRT), mainly dialysis. ${ }^{2}$ The number of cases increases by $8 \%$ on average every year, mainly driven by increased occurrences of diabetes and hypertension. ${ }^{1}$ Being a costly treatment, the increase represents a major challenge to health care resources, especially in developing countries. ${ }^{2,3}$ Similarly, there has been a marked increase in the incidence and prevalence of ESRD in Saudi Arabia over the last 3 decades, with approximately 14,000 patients currently on dialysis, mainly hemodialysis. ${ }^{4}$ 
Several psychiatric ailments have been described among dialysis patients including depression, anxiety, adjustment disorders, and cognitive impairment. ${ }^{5-7}$ The prevalence of depression and anxiety has been discussed in several studies, with a wide range of variabilities probably due to the populations examined, methods of diagnosis, and dialysis modality. ${ }^{7,8}$ Depression has been specifically linked to a poor quality of life and increased risk of mortality. ${ }^{9,10}$ Additionally, psychiatric and physical comorbidities have been reported to greatly affect the quality of life in dialysis patients. ${ }^{5,11}$

Given the lengthy and complicated nature of RRT, adherence to different aspects of treatment including dialysis sessions, medications, and diet/fluid restrictions is very critical for patient survival and other RRT outcomes. ${ }^{12}$ Despite the variability in prevalence estimates, nonadherence has been shown to be prevalent in dialysis patients, ${ }^{12-14}$ and has been linked to higher mortality, excess health care utilization, and poor quality of life. ${ }^{15,16} \mathrm{~A}$ number of reports suggest the link between depression and nonadherence. ${ }^{17-19}$ However, the relationship between nonadherence and psychiatric disorders or psychological determinants has been inadequately examined. ${ }^{12}$ Additionally, there is a lack of local data on the prevalence and determinants of nonadherence among dialysis patients in Saudi Arabia. ${ }^{20}$ The objective of this study was to examine the prevalence of psychological ailments including depression, anxiety, insecure attachment style, and cognitive impairment and their associations with adherence to the recommended management of ESRD among patients on maintenance dialysis.

\section{Patients and methods}

\section{Setting}

This study was conducted with patients receiving dialysis at one of the four major hospitals in Riyadh, Saudi Arabia (i.e. King Saud University Medical City, King Abdulaziz Medical City [National Guard], King Salman Center for Kidney Diseases, and Prince Sultan Military Medical City). The total number of patients on dialysis served by these hospitals is approximately 1,000. All of the included hospitals are large teaching hospitals with the exception of King Salman Center for Kidney Diseases, which is a governmentally funded center under the authority of the Ministry of Health. All of the included hospitals provide free dialysis services to their target populations.

\section{Study design}

A cross-sectional observational study was conducted from 2014 to 2015. The study obtained Ethical Approval from the institutional review board at the Faculty of Medicine at King Saud University in Riyadh, as well as administrative approvals from respective hospitals.

\section{Population}

Consecutive patients receiving dialysis for at least three months in one of the included hospitals were asked to join the study. Those who gave written informed consent, irrespective of their gender or type of dialysis the investigators received, were interviewed by the investigators of this study, they completed a structured study questionnaire, and completed assessment tools. Those who were under 18 years of age and those who were unable to answer the study questionnaire or complete the assessment tools due to disease or disability (e.g., dementia, deafness, or blindness) were excluded from the study.

\section{Data collection}

A structured study questionnaire was developed, and it included socio-demographic characteristics, clinical profile related to renal failure and dialysis, medical history, and psychiatric history before and after the diagnosis of renal failure. Trained staff, who were not involved in patient care, were responsible for conducting interviews. The visual analog scale (VAS) numbered from 1 to 10 was used as a general self-report questionnaire ${ }^{21-23}$ to assess patients' adherence with care plans recommended by the treating physician, including attending dialysis sessions, taking prescribed medications, following food/fluid restrictions, and exercise recommendations. A VAS score of 8 or more was considered as adherence while a score of less than 8 was considered nonadherence. This cut-off score has been used in several previously published studies among various medical populations..$^{22,24,25}$ A previously validated Arabic copy of the 9-item patient health questionnaire (PHQ-9) was used to screen for depression. ${ }^{26}$ The PHQ-9 is the depression module of the self-administered version of the Primary Care Evaluation of Mental Disorders (PRIME-MD) diagnostic instrument for common mental disorders. ${ }^{27}$ It scores each of the 9 DSMIV (Diagnostic and Statistical Manual of Mental Disorders, 4 th Edition) criteria as "0" (not at all) to " 3 " (nearly every day) ${ }^{27}$ A previously validated Arabic copy of the Hospital Anxiety and Depression (HAD) scale-anxiety was used to screen for anxiety. ${ }^{28} \mathrm{~A}$ previously validated Arabic copy of the Montreal Cognitive Assessment (MoCA) was used to screen for cognitive dysfunction. ${ }^{29}$ The question regarding suicidal thoughts was derived from the ninth item of the PHQ-9 scale.

The Experiences in Close Relationships - Modified 16 (ECR-M16) scale was used to measure the patients' 
relationship with others in the context of intimate relationships and social support. ${ }^{30}$ Relationship styles describe the way an individual utilizes close social supports during illness crisis and have been associated to mortality and adherence in other medical illnesses. ${ }^{31}$ The ECR-M16, has been validatedagainst the longer 36-item ECR which is valid and reliable self-report measure of adult attachment that has been used in hundreds of studies. ${ }^{32}$

The original English version of ECR-M16 was translated into Arabic by two bilingual linguistic specialists and then back into English by two other bilingual linguistic specialists. During each stage, both translated versions were compared with the original scale by the investigators and any differences were discussed and resolved to obtain one final version. A final copy in Arabic was tested on 20 patients and the wording of some questions was modified based on voluntary feedback. The Arabic version of ECR-M16 that was used was reliable, as shown by Cronbach's Alpha which was 0.736 for the 8 items of anxiety and 0.627 for the 8 items of avoidance. The ECR anxiety score was significantly and positively correlated with the PHQ-9 score $(r=0.396, p<0.001)$ and the HAD anxiety score $(r=0.536, p<0.001)$. The ECR avoidance score was significantly and positively correlated with the HAD anxiety score $(r=0.130, p=0.047)$ but not the PHQ-9 score $(r=0.098, p=0.133)$.

\section{Statistical analysis}

The data are presented as frequencies and percentages for categorical data and mean and standard deviation (SD) for continuous data. The tools were analyzed both as continuous variables as well as meaningful categories. For the PHQ-9 score, which ranged between 0 and 27 , a score of 10 or above indicated depression. The seven odd questions of the HAD anxiety scale were used to create a score ranging from 0 to 21 with a score above 7 indicating anxiety. The ECR-M16, produces two measures of attachment style, one related to anxious attachment and another one related to avoidant attachment. Each attachment style score ranges from 8 to 56 with higher style scores representing greater relationship style insecurity. A MoCA score less than 26 (out of maximum of 30) was considered as cognitive impairment. Significant differences between adherent and nonadherent groups with regards to demographics, clinical characteristics, comorbidity, and psychiatric tools were tested using the chi-square test or Fisher's exact test (as appropriate) for categorical data and Student's $t$-test for continuous data. Adjusted mean values of the examined psychiatric scores were calculated using general linear regression models with adherence status as fixed factors. Age, gender, and other clinical characteristics that showed significant (or trend of) associations with nonadherence were treated randomly or as covariates, as appropriate. All $p$-values were two-tailed; $p$-value $<0.05$ was considered as significant. SPSS software (release 20.3, Armonk, NY: IBM Corp) was used for all statistical analyses.

\section{Results}

A total 234 patients (147 males and 87 females) were included in this analysis. As shown in Figure 1, the majority of the patients responded positively to the VAS assessing the patient adherence to the physician-recommended care plans, dialysis sessions, medications, exercise, and diet/fluid restrictions, with $189(80.8 \%)$ considered as adherent and $45(19.2 \%)$ considered as nonadherent.

Demographic characteristics of the study patients are shown in Table 1. None of the above demographic characteristics were significantly associated with nonadherence, with the exception of younger patients that showed a trend of association with nonadherence $(p=0.060)$.

Clinical/social characteristics of the included patients are shown in Table 2. Some patients believed that their renal failure was related to psychological stress $(19 \%)$ or non-medical causes such as the evil eye, possession, or black magic (31\%). In addition to dialysis, one-third (32\%) of the patients were using alternative medicine such as herbs $(76 \%)$, religious ruqyah (faith healing) (40\%), and cauterization (13\%). Of the clinical/social characteristics, non-satisfaction with provided dialysis services ( $p=0.006$ ) and to a lesser extent believing in supernatural causes of renal failure (0.064) were significantly associated with nonadherence.

Medical and psychological comorbidity of the included patients are shown in Table 3. Only 3\% of the patients reported having a psychiatric disorder before the diagnosis of

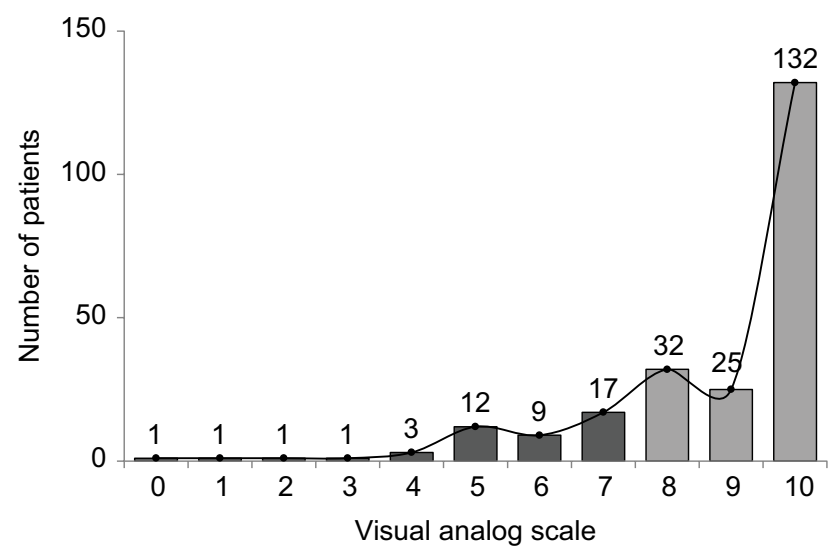

Figure I Patient response to visual analog scale assessing adherence to care plans, dialysis sessions, and medications.

Notes: Dark columns indicate non-adherence; gray columns indicate adherence. 
Table I Demographic characteristics of dialysis patients by adherence status

\begin{tabular}{|c|c|c|c|c|}
\hline Characteristics & $\begin{array}{l}\text { Adherence } \\
\mathrm{N}=189 \text { (\%) }\end{array}$ & $\begin{array}{l}\text { Nonadherence } \\
\mathrm{N}=45 \text { (\%) }\end{array}$ & $\begin{array}{l}\text { Total } \\
\mathrm{N}=234 \text { (\%) }\end{array}$ & p-value \\
\hline \multicolumn{5}{|l|}{ Age, years } \\
\hline Mean \pm SD & $50.6 \pm 14.9$ & $45.8 \pm 15.8$ & $49.7 \pm 15.2$ & 0.060 \\
\hline $18-44$ & $58(30.7)$ & $21(46.7)$ & 79 (33.8) & 0.124 \\
\hline $45-59$ & $74(39.2)$ & $14(3 \mid .1)$ & $88(37.6)$ & \\
\hline$\geq 60$ & $57(30.2)$ & $10(22.2)$ & $67(28.6)$ & \\
\hline \multicolumn{5}{|l|}{ Gender } \\
\hline Male & $117(61.9)$ & $30(66.7)$ & $147(62.8)$ & 0.552 \\
\hline Female & $72(38.1)$ & $15(33.3)$ & $87(37.2)$ & \\
\hline \multicolumn{5}{|l|}{ Marital status } \\
\hline Married & $136(72.0)$ & $29(64.4)$ & $165(70.5)$ & 0.505 \\
\hline Single & $33(17.5)$ & $10(22.2)$ & $43(18.4)$ & \\
\hline Divorced & $8(4.2)$ & $4(8.9)$ & $12(5.1)$ & \\
\hline Widow & $12(6.3)$ & $2(4.4)$ & $14(6.0)$ & \\
\hline Number of children & $5.7 \pm 3.9$ & $4.9 \pm 3.0$ & $5.6 \pm 3.7$ & 0.458 \\
\hline \multicolumn{5}{|l|}{ Educational status } \\
\hline Less than secondary & $109(58.0)$ & $20(44.4)$ & $129(55.4)$ & 0.252 \\
\hline Secondary & $40(21.3)$ & $12(26.7)$ & $52(22.3)$ & \\
\hline College or higher & $39(20.7)$ & $13(28.9)$ & $52(22.3)$ & \\
\hline \multicolumn{5}{|l|}{ Occupation } \\
\hline Employed & $67(36.8)$ & $23(5 I . I)$ & $90(39.6)$ & 0.143 \\
\hline Unemployed & $80(44.0)$ & $16(35.6)$ & $96(42.3)$ & \\
\hline Housewife & $32(17.6)$ & $4(8.9)$ & $36(15.9)$ & \\
\hline Student & $3(1.6)$ & $2(4.4)$ & $5(2.2 \%)$ & \\
\hline \multicolumn{5}{|l|}{ Nationality } \\
\hline Saudi & I8I (95.8) & $43(95.6)$ & $224(95.7)$ & $>0.999$ \\
\hline Non-Saudi & $8(4.2)$ & $2(4.4)$ & $10(4.3)$ & \\
\hline \multicolumn{5}{|l|}{ Monthly income (SAR) } \\
\hline$<5,000$ & $70(39.3)$ & $15(33.3)$ & $85(38.1)$ & 0.514 \\
\hline $5,000-10,000$ & $67(37.6)$ & $16(35.6)$ & $83(37.2)$ & \\
\hline$>10,000$ & $41(23.0)$ & $14(31.1)$ & $55(24.7)$ & \\
\hline \multicolumn{5}{|l|}{ Housing type } \\
\hline Own & $117(65.0)$ & $26(57.8)$ & $143(63.6)$ & 0.509 \\
\hline Rent & $62(34.4)$ & $19(42.2)$ & $81(36.0)$ & \\
\hline Others & $\mathrm{I}(0.6)$ & $0(0.0)$ & $\mathrm{I}(0.4)$ & \\
\hline Number of household adults & $4.5 \pm 3.3$ & $4.0 \pm 2.5$ & $4.4 \pm 3.2$ & 0.609 \\
\hline \multicolumn{5}{|l|}{ Regular exercise } \\
\hline No & $150(79.4)$ & $38(84.4)$ & $188(80.3)$ & $0.44 I$ \\
\hline Yes & $39(20.6)$ & $7(15.6)$ & $46(19.7)$ & \\
\hline \multicolumn{5}{|l|}{ Current smoking } \\
\hline No & $158(83.6)$ & $38(84.4)$ & $196(83.8)$ & 0.890 \\
\hline Yes & $31(16.4)$ & $7(15.6)$ & $38(16.2)$ & \\
\hline \multicolumn{5}{|c|}{ Using alcohol or other substances } \\
\hline No & I84 (97.4) & $44(97.8)$ & $228(97.4)$ & $>0.999$ \\
\hline Yes & $5(2.6)$ & $\mathrm{I}(2.2)$ & $6(2.6)$ & \\
\hline
\end{tabular}

renal failure. However, $42 \%$ of the patients reported a change in their psychological status but only 5\% were regularly seeing a psychiatrist. Approximately, $7 \%$ of the patients had been diagnosed with psychiatric disorders (mainly depression) after the diagnosis of renal failure, with $44 \%$ of those diagnosed with psychiatric disorders taking psychiatric medications. Approximately $10 \%$ of the patients reported having frequent thoughts that they would be better off dead or of hurting themselves in some way in the last 2 weeks, before the survey. Increased comorbidity and diabetes, in patients, were negatively associated with nonadherence $(p=0.022$ and $p=0.040$, respectively).

The psychiatric examination results of the examined patients are shown in Table 4. The average QPH9 score was $4.90 \pm 4.81$ with approximately $18 \%$ of the patients having depression (score of 10 or more out of 27 ). The average HAD anxiety score was $3.32 \pm 3.88$ with approximately $13 \%$ of the patients having anxiety (score of more than 7 out of 21 ). The 
Table 2 Clinical characteristics of patients by adherence status

\begin{tabular}{|c|c|c|c|c|}
\hline Characteristics & $\begin{array}{l}\text { Adherence } \\
\mathrm{N}=189 \text { (\%) }\end{array}$ & $\begin{array}{l}\text { Nonadherence } \\
\mathrm{N}=45 \text { (\%) }\end{array}$ & $\begin{array}{l}\text { Total } \\
\mathrm{N}=\mathbf{2 3 4} \text { (\%) }\end{array}$ & $p$-value \\
\hline \multicolumn{5}{|l|}{ Years of renal failure } \\
\hline Mean \pm SD & $7.0 \pm 7.4$ & $6.0 \pm 5.8$ & $6.8 \pm 7.1$ & 0.535 \\
\hline$\leq 5$ & $108(57.4)$ & $29(64.4)$ & $137(58.8)$ & 0.392 \\
\hline$>5$ & $80(42.6)$ & $16(35.6)$ & $96(4 I .2)$ & \\
\hline \multicolumn{5}{|c|}{ Knowledge of renal failure etiology } \\
\hline No & $77(40.7)$ & $19(42.2)$ & $96(41.0)$ & 0.856 \\
\hline Yes & $112(59.3)$ & $26(57.8)$ & I 38 (59.0) & \\
\hline Hypertension & $40(35.7)$ & II (42.3) & $51(37.0)$ & 0.530 \\
\hline Diabetes & $21(18.8)$ & $3(11.5)$ & $24(17.4)$ & 0.418 \\
\hline Hereditary & $7(6.3)$ & $\mathrm{I}(3.8)$ & $8(5.8)$ & 0.707 \\
\hline Renal atrophy & $9(8.0)$ & $0(0.0)$ & $9(6.5)$ & 0.208 \\
\hline Medications & $9(8.0)$ & $0(0.0)$ & $9(6.5)$ & 0.208 \\
\hline Inflammation & $4(3.6)$ & $2(7.7)$ & $6(4.3)$ & 0.594 \\
\hline Other & $29(25.9)$ & $7(26.9)$ & $36(26.1)$ & 0.914 \\
\hline \multicolumn{5}{|l|}{ Perceived related conditions } \\
\hline Psychological stress & $35(18.7)$ & $9(20.0)$ & $44(19.0)$ & 0.844 \\
\hline Evil eye/possession/black magic & $53(28.0)$ & $19(42.2)$ & $72(30.8)$ & 0.064 \\
\hline \multicolumn{5}{|l|}{ Family history of renal failure } \\
\hline No & $|4|(75.0)$ & $33(73.3)$ & $174(74.7)$ & 0.817 \\
\hline Yes & $47(25.0)$ & $12(26.7)$ & $59(25.3)$ & \\
\hline \multicolumn{5}{|l|}{ Alternative medicine use } \\
\hline No & |3| (69.3) & $28(62.2)$ & $159(67.9)$ & 0.360 \\
\hline Yes & $58(30.7)$ & $17(37.8)$ & $75(32.1)$ & \\
\hline \multicolumn{5}{|l|}{ Years of dialysis } \\
\hline Mean \pm SD & $5.6 \pm 7.0$ & $5.7 \pm 5.6$ & $5.6 \pm 6.7$ & 0.304 \\
\hline$\leq 5$ & $120(67.0)$ & $28(66.7)$ & $148(67.0)$ & 0.963 \\
\hline$>5$ & $59(33.0)$ & $14(33.3)$ & $73(33.0)$ & \\
\hline \multicolumn{5}{|l|}{ Type of dialysis } \\
\hline Peritoneal & $14(7.4)$ & $\mathrm{I}(2.2)$ & $15(6.4)$ & 0.314 \\
\hline Hemodialysis & $175(92.6)$ & $44(97.8)$ & $219(93.6)$ & \\
\hline \multicolumn{5}{|c|}{ Satisfaction with provided dialysis } \\
\hline Excellent & I 43 (75.7) & $25(55.6)$ & $168(7 \mid .8)$ & 0.006 \\
\hline Good & $38(20.1)$ & $18(40.0)$ & $56(23.9)$ & \\
\hline Not bad & $7(3.7)$ & $0(0.0)$ & $7(3.0)$ & \\
\hline Bad & $\mathrm{I}(0.5)$ & $2(4.4)$ & $3(1.3)$ & \\
\hline \multicolumn{5}{|l|}{ Problems getting to dialysis unit } \\
\hline No & $109(58.0)$ & $21(46.7)$ & $130(55.8)$ & 0.170 \\
\hline Yes & $79(42.0)$ & $24(53.3)$ & $103(44.2)$ & \\
\hline \multicolumn{5}{|l|}{ Support from family or friends } \\
\hline No & $13(6.9)$ & $4(8.9)$ & $17(7.3)$ & 0.749 \\
\hline Yes & $175(93.1)$ & $4 \mid(9 l .1)$ & $216(92.7)$ & \\
\hline
\end{tabular}

average ECR-M16 score was $27.99 \pm 10.87$ for anxiety and 21.71 $\$ 9.06$ for avoidance (out of a maximum of 56). The average MoCA cognitive function was 19.38 \pm 6.90 with approximately $77 \%$ of the patients being cognitively impaired (score less than 26 out of 30 ). Nonadherence was significantly associated with higher levels of depression and anxiety ( $p<0.001$ for both). This was evident when using the relevant score as a continuous or categorical variable. Moreover, the statistically significant associations remained unaffected after adjusting the mean values for differences in age, gender, and other clinical characteristics that showed significant (or trend of) associations with nonadherence. Nonadherence was associated with higher levels of ECR-M16, but the difference was significant for anxious subtype $(p=0.001)$ but not for avoidance subtype $(p=0.400)$. Overall, there was a trend of association ( $p=0.085)$ between nonadherence and a sense of insecurity. The slight difference in the MoCA score by adherence status disappeared after adjustment (for the above factors), and nonadherence was not significantly associated with cognitive impairment $(p=0.266)$

\section{Discussion}

We report a nonadherence rate of approximately 19\% amongst our dialysis patients. While our rate is considered 
Table 3 Medical and psychological comorbidity of patients by adherence status

\begin{tabular}{|c|c|c|c|c|}
\hline Medical and psychological comorbidity & $\begin{array}{l}\text { Adherence } \\
\mathrm{N}=189 \text { (\%) }\end{array}$ & $\begin{array}{l}\text { Nonadherence } \\
\mathbf{N}=45 \text { (\%) }\end{array}$ & $\begin{array}{l}\text { Total } \\
\mathbf{N}=234 \text { (\%) }\end{array}$ & $p$-value \\
\hline \multicolumn{5}{|l|}{ Medical comorbidity } \\
\hline Comorbidity number & $1.9 \pm 1.2$ & $1.4 \pm 1.0$ & $1.8 \pm 1.2$ & 0.022 \\
\hline None & $20(10.6)$ & $8(17.8)$ & $28(12.0)$ & 0.069 \\
\hline$<3$ & $120(63.5)$ & $32(71.1)$ & $152(65.0)$ & \\
\hline$\geq 3$ & 49 (25.9) & $5(I I . I)$ & $54(23.1)$ & \\
\hline Hypertension & $139(73.5)$ & $31(68.9)$ & $170(72.6)$ & 0.529 \\
\hline Diabetes mellitus & $68(36.0)$ & $9(20.0)$ & $77(32.9)$ & 0.040 \\
\hline Asthma & $5(2.6)$ & $\mathrm{I}(2.2)$ & $6(2.6)$ & $>0.999$ \\
\hline Cardiovascular disease & $30(15.9)$ & $2(4.4)$ & $32(13.7)$ & 0.045 \\
\hline Hyperlipidemia & $12(6.3)$ & $3(6.7)$ & $15(6.4)$ & $>0.999$ \\
\hline Hyperthyroidism & $\mathrm{I}(0.5)$ & $\mathrm{I}(2.2)$ & $2(0.9)$ & 0.348 \\
\hline Hypothyroidism & $12(6.3)$ & $2(4.4)$ & $14(6.0)$ & 0.745 \\
\hline Hepatitis B & $6(3.2)$ & $0(0.0)$ & $6(2.6)$ & 0.360 \\
\hline Hepatitis C & $19(10.1)$ & I (2.2) & $20(8.5)$ & 0.135 \\
\hline Epilepsy & $2(1.1)$ & $0(0.0)$ & $2(0.9)$ & $>0.999$ \\
\hline Anemia & $0(0.0)$ & $\mathrm{I}(2.2)$ & $\mathrm{I}(0.4)$ & 0.192 \\
\hline Others & $49(25.9)$ & II (24.4) & $60(25.6)$ & 0.838 \\
\hline \multicolumn{5}{|c|}{ Psychiatric disorder before the diagnosis of renal failure } \\
\hline No & $183(96.8)$ & $44(97.8)$ & $227(97.0)$ & $>0.999$ \\
\hline Yes & $6(3.2)$ & $\mathrm{I}(2.2)$ & $7(3.0)$ & \\
\hline \multicolumn{5}{|c|}{ Psychiatric status after the diagnosis of renal failure } \\
\hline Change in psychological status & $76(40.6)$ & $22(48.9)$ & $98(42.2)$ & 0.315 \\
\hline Seeing a psychiatrist & $9(4.8)$ & $2(4.4)$ & II (4.7) & $>0.999$ \\
\hline Diagnosed with psychiatric disorder & $12(6.4)$ & $4(8.9)$ & $16(6.9)$ & 0.743 \\
\hline Depression & $6(50.0)$ & $2(50.0)$ & $8(50.0)$ & 0.171 \\
\hline Others & $\mathrm{I}(8.3)$ & $2(50.0)$ & $3(18.8)$ & \\
\hline Unknown & $5(4 I .7)$ & $0(0.0)$ & $5(31.3)$ & \\
\hline Taking psychiatric medications & $6(50.0)$ & I (25.0) & $7(43.8)$ & 0.585 \\
\hline \multicolumn{5}{|c|}{$\begin{array}{l}\text { Thoughts that he/she would be better off dead or } \\
\text { hurting him/herself in some way }\end{array}$} \\
\hline Not at all & $172(9 \mid .0)$ & $38(84.4)$ & $210(89.7)$ & 0.067 \\
\hline Several days & $12(6.3)$ & $4(8.9)$ & $16(6.8)$ & \\
\hline More than half the days & $2(1.1)^{\prime}$ & $3(6.7)$ & $5(2.1)^{\prime}$ & \\
\hline Nearly every day & $3(1.6)$ & $0(0.0)$ & $3(1.3)$ & \\
\hline
\end{tabular}

within the range reported by different studies, wide variability in estimating the prevalence of nonadherence has been reported ${ }^{12-14}$ due to lack of a standard definition and assessment tools for identifying nonadherence. ${ }^{12,15}$ For example, in a large international study with approximately 15,000 hemodialysis patients in the US, Europe, and Japan, nonadherence was estimated at $4 \%$ for skipping sessions, $13 \%$ for shortening sessions, $14 \%$ for high phosphate, and $20 \%$ for excessive fluid retention. ${ }^{13}$ Additionally, in a recent systematic review of 25 studies performed on peritoneal dialysis patients, nonadherence has been estimated at $3-53 \%$ for dialysis procedure, $4-85 \%$ for medication, and $15-67 \%$ for diet/fluid restriction. ${ }^{12}$ In addition to psychosocial disorders, especially depression, nonadherence in dialysis patients was suggested to be caused by low self-efficacy, limited social support, limited dialysis-related knowledge, and negative perceptions of the disease and its treatment.
Our dialysis patients suffered a considerable burden of psychological disorders with $18 \%$ having depression symptoms and $13 \%$ having anxiety symptoms. The current rates were similar or slightly lower than rates documented in several previous studies. For example, the prevalence of depression among dialysis patients has been estimated in the majority of the studies between $15 \%$ and $30 \%$. Additionally, the prevalence of anxiety, which has not been examined as much as depression, among dialysis patients has been estimated between $11 \%$ and $26 \%{ }^{33}$ However, using different assessment tools and even different cutoff levels within the same tool, a wide range of depression rates ranging between $5 \%$ and $70 \%{ }^{8,34}$ and anxiety rates between $10 \%$ and $50 \%$ have been reported. ${ }^{7,33}$ The prevalence of both depression and anxiety were obviously several folds higher in dialysis patients than in the general population. ${ }^{7}$ It has been shown that ESRD symptomatology, the need to comply with treatment 
Table 4 Patient psychiatric examinations by adherence status

\begin{tabular}{|c|c|c|c|c|}
\hline Patient psychiatric examinations & $\begin{array}{l}\text { Adherence } \\
N=189(\%)\end{array}$ & $\begin{array}{l}\text { Nonadherence } \\
\mathrm{N}=45 \text { (\%) }\end{array}$ & $\begin{array}{l}\text { Total } \\
\mathrm{N}=234 \text { (\%) }\end{array}$ & $p$-value \\
\hline \multicolumn{5}{|l|}{ QPH9 score } \\
\hline Crude mean $( \pm S D)$ & $4.27 \pm 4.4 \mathrm{I}$ & $7.56 \pm 5.53$ & $4.90 \pm 4.81$ & $<0.001$ \\
\hline Adjusted* mean $( \pm \mathrm{SE})$ & $5.75 \pm 0.81$ & $8.73 \pm 0.96$ & $7.24 \pm 0.81$ & $<0.001$ \\
\hline \multicolumn{5}{|l|}{ QPH9 depression groups } \\
\hline Normal (0-9) & $164(86.8)$ & $28(62.2)$ & $192(82.1)$ & $<0.001$ \\
\hline Depression $(\geq 10)$ & $25(13.2)$ & $17(37.8)$ & $42(17.9)$ & \\
\hline \multicolumn{5}{|l|}{ HAD anxiety score } \\
\hline Crude mean $( \pm S D)$ & $2.7 I \pm 3.33$ & $5.89 \pm 4.88$ & $3.32 \pm 3.88$ & $<0.001$ \\
\hline Adjusted* mean $( \pm \mathrm{SE})$ & $3.23 \pm 0.64$ & $6.28 \pm 0.76$ & $4.75 \pm 0.64$ & $<0.001$ \\
\hline \multicolumn{5}{|l|}{ HAD anxiety groups } \\
\hline Normal (0-7) & I7I (90.5) & $32(7 \mid . I)$ & $203(86.8)$ & 0.001 \\
\hline Anxiety (>7) & $18(9.5)$ & $13(28.9)$ & $31(13.2)$ & \\
\hline \multicolumn{5}{|l|}{ ECR-MI6 } \\
\hline Crude anxiety mean $( \pm S D)$ & $26.92 \pm 10.67$ & $32.5 I \pm 10.64$ & $27.99 \pm 10.87$ & 0.001 \\
\hline Adjusted* anxiety mean $( \pm S E)$ & $27.66 \pm 1.99$ & $33.19 \pm 2.36$ & $30.42 \pm 1.98$ & 0.003 \\
\hline Crude avoidance mean $( \pm S D)$ & $21.45 \pm 9.03$ & $22.80 \pm 9.22$ & $21.71 \pm 9.06$ & 0.400 \\
\hline Adjusted* avoidance mean $( \pm \mathrm{SE})$ & $20.77 \pm 1.70$ & $22.24 \pm 2.02$ & $21.51 \pm 1.69$ & 0.357 \\
\hline \multicolumn{5}{|l|}{ ECR-MI 6 groups } \\
\hline Secure & $53(28.0)$ & $7(I 5.6)$ & $60(25.6)$ & 0.109 \\
\hline Dismissing & $48(25.4)$ & $8(17.8)$ & $56(23.9)$ & \\
\hline Preoccupied & $43(22.8)$ & $14(31.1)$ & $57(24.4)$ & \\
\hline Fearful & $45(23.8)$ & $16(35.6)$ & $61(26.1)$ & \\
\hline \multicolumn{5}{|l|}{ ECR-MI 6 groups } \\
\hline Secure & $53(28.0)$ & $7(15.6)$ & $60(25.6)$ & 0.085 \\
\hline Insecure & $136(72.0)$ & $38(84.4)$ & $174(74.4)$ & \\
\hline \multicolumn{5}{|l|}{ MoCA score } \\
\hline Crude mean $( \pm S D)$ & $19.05 \pm 6.86$ & $20.73 \pm 7.02$ & $19.38 \pm 6.90$ & 0.078 \\
\hline Adjusted* mean $( \pm \mathrm{SE})$ & $20.33 \pm 1.09$ & $19.99 \pm 1.29$ & $20.16 \pm 1.08$ & 0.743 \\
\hline \multicolumn{5}{|l|}{ MoCA cognitive function groups } \\
\hline Normal $(\geq 26)$ & $40(21.2)$ & $13(28.9)$ & $53(22.6)$ & 0.266 \\
\hline Cognitive impairment $(<26)$ & I 49 (78.8) & $32(7 I . I)$ & I8I (77.4) & \\
\hline
\end{tabular}

Notes: *Mean values were adjusted for age, gender, the degree of satisfaction with provided dialysis services, belief in supernatural causes, number of medical comorbidities, and presence of diabetes.

Abbreviations: QPH9, Patient Health Questionnaire; HAD, Hospital Anxiety and Depression scale; ECR, Experiences in Close Relationships scale; MoCA, Montreal Cognitive Assessment; SD, standard deviation; SE, standard error. ECR-MI6, Experiences in Close Relationships-Modified I6.

aspects, hospitalizations, comorbidity, fear of disability and shortened lifespan represent significant stressors that increase the risk of both depression and anxiety. ${ }^{35}$ The burdens of psychiatric disorders on dialysis patients can increase their risk of morbidity and lead to poor quality of life. ${ }^{9-11}$

Both depression and anxiety in the current study were independently associated with nonadherence to dialysis sessions, medications, and diet/fluid restrictions. Similarly, the presence of depression and to a lesser extent anxiety was associated, in previous studies, with poor adherence to different aspects of ESRD management. ${ }^{17-19}$ For example, depressive symptoms were independently associated with missed (relative risk 1.21), or shortened (relative risk 1.08) hemodialysis treatments. ${ }^{18}$ Similarly, Beck Depression Inventory scores were significantly higher $(17.3$ versus $12.9, p<0.001)$ with nonadherence defined as missed session, fluid retention, or higher phosphate. ${ }^{16}$ Moreover, symptoms of depression were a significant precursor for subsequent life-threatening decisions to withdraw from dialysis. ${ }^{36}$

Three-quarters of our dialysis patients had cognitive impairment. This was similar to the findings from previous studies where up to $70 \%$ of dialysis patients had moderate to severe cognitive impairment. ${ }^{37,38}$ However, our rate of cognitive impairment was higher than reported by other studies. ${ }^{6,39}$ Cognitive impairment in our patients was strongly associated with older age (data not shown). Similarly, aging in dialysis patients and the presence of cerebrovascular diseases were shown to play a major role in the pathophysiology of cognitive impairment. ${ }^{38,40}$ Although cognitive impairment was suggested in some studies as a risk of unintentional (due to forgetfulness) nonadherence or even withdrawal from dialysis, ${ }^{17,38}$ we could not detect any 
significant association between cognitive impairment and nonadherence in our patients. Similarly, Ibrahim et al failed to detect a significant association between nonadherence and cognitive impairment assessed using blessed dementia memory test with chronic hemodialysis patients. ${ }^{16}$ The detachment style in the current study was more evident in anxiety (28.0 out of 56) than avoidance ( 21.7 out of 56). This may reflect the fact that more than $90 \%$ of patients reported receiving support from their family or friends. The high level of family and friend support for our patients (which is expected in a traditionally extended family culture in Saudi Arabia) may have obscured any association between avoidant (dismissing) detachment style and nonadherence. However, the independent association between anxiety (preoccupied) detachment style and nonadherence corroborates the anxiety findings shown.

With a few exceptions, sociodemographic and clinical characteristics of our patients did not play a major role in nonadherence. For example, low satisfaction, little comorbidity, and to a lesser extent younger age were associated with nonadherence. In contrast, a systematic review of 25 studies examining nonadherence among patients on peritoneal dialysis found that nonadherence was linked to employment, the male gender, and longer duration of dialysis in addition to younger age patients and poor satisfaction with treatment. ${ }^{12}$ Additionally, a higher number of comorbidity was negatively associated with nonadherence fluid intake among Chinese hemodialysis patients. ${ }^{39}$ Similar to our study, some studies failed to detect any impact of gender, education, or employment on nonadherence. ${ }^{16,38}$

This study has several strengths, including it being the first local study to estimate the prevalence and the associations of psychosocial predictors with nonadherence, using multiple validated psychosocial outcomes, in a multicenter experience, with adjustments for relevant demographic and clinical characteristics. Nevertheless, we acknowledge a number of limitations. Being a cross-sectional study makes it difficult to ascertain causality between psychosocial predictors and nonadherence. As our patients were recruited through convenience sampling, the findings should be projected to Saudi dialysis patients with caution. Also, with the use of self-reported questionnaires, the possibility of recall bias cannot be excluded. Moreover, the use of VAS did not enable us to quantify the degree and quality of nonadherence. Finally, lack of a universal definition of nonadherence and the use of different tools to detect psychosocial disorders complicates comparisons between this study and other nonadherence studies.

\section{Conclusion}

Nonadherence to different aspects of ESRD continues to be a serious problem amongst dialysis patients, which is closely linked to depression and anxiety. As the nonadherence problem is multifactorial, no single strategy is believed to yield universal and/or lasting improvements in adherence. ${ }^{42}$ The findings of the current study reemphasize the need to focus on early detection and management of psychosocial disorders which are considered major contributors of nonadherence. Additionally, focusing on the patient-provider relationship with the aim to identify barriers and improve patient satisfaction may be an important candidate prevention strategy. ${ }^{42}$

\section{Acknowledgments}

The authors would like to acknowledge the support they received from the College of Medicine Research Center, Deanship of Scientific Research, King Saud University. Furthermore, the authors express their gratitude to Dr Aiman El-Saed for his assistance in data analysis and manuscript writing, and to Ms Fatima Jama for her assistance with data entry.

\section{Authors' contributions}

FDA designed the study; supervised the data collection, entry and statistical analysis; and co-wrote the final draft of the manuscript. All authors participated effectively in designing the study, data collection and analysis, writing and critically revising the paper. All authors read and approved the final manuscript.

\section{Disclosure}

The authors have no conflicts of interest in this work.

\section{References}

1. Schieppati A, Remuzzi G. Chronic renal diseases as a public health problem: Epidemiology, social, and economic implications. Kidney Int Suppl. 2005;68(98):S7-S10.

2. Anand S, Bitton A, Gaziano T. The gap between estimated incidence of end-stage renal disease and use of therapy. Barengo NC, ed. PLoS One. 2013;8(8):e72860.

3. Lee H, Manns B, Taub K, et al. Cost analysis of ongoing care of patients with end-stage renal disease: the impact of dialysis modality and dialysis access. Am J Kidney Dis. 2002;40(3):611-622.

4. Saudi Center for Organ Transplantation. Dialysis in the Kingdom of Saudi Arabia. Available from: http://www.sjkdt.org/text.asp 2012/23/4/881/98196. Accessed October 21, 2016.

5. Jadhav BS, Dhavale HS, Dere SS, Dadarwala DD. Psychiatric morbidity, quality of life and caregiver burden in patients undergoing hemodialysis. Med J Dr DY Patil Univ. 2014;7(6):722.

6. Dong J, Pi H, Xiong Z, et al. Depression and cognitive impairment in peritoneal dialysis: a multicenter cross-sectional study. Am J Kidney Dis. 2016;67(1):111-118. 
7. Feroze U, Martin D, Kalantar-Zadeh K, Kim JC, Reina-Patton A, Kopple JD. Anxiety and depression in maintenance dialysis patients: preliminary data of a cross-sectional study and brief literature review. J Ren Nutr. 2012;22(1):207-210.

8. Chilcot J, Wellsted D, Da Silva-Gane M, Farrington K. Depression on dialysis. Nephron Clin Pract. 2008;108(4):c256-c264.

9. Drayer RA, Piraino B, Reynolds CF, et al. Characteristics of depression in hemodialysis patients: symptoms, quality of life and mortality risk. Gen Hosp Psychiatry. 2006;28(4):306-312.

10. Kimmel PL, Peterson RA, Weihs KL, et al. Multiple measurements of depression predict mortality in a longitudinal study of chronic hemodialysis outpatients. Kidney Int. 2000;57(5):2093-2098.

11. Birmelé B, Le Gall A, Sautenet B, Aguerre C, Camus V. Clinical, sociodemographic, and psychological correlates of health-related quality of life in chronic hemodialysis patients. Psychosomatics. 2012;53(1): 30-37.

12. Griva K, Lai AY, Lim HA, Yu Z, Foo MWY, Newman SP. Non-adherence in patients on peritoneal dialysis: a systematic review. PLoS One. 2014; 9(2):e89001

13. Saran R, Bragg-Gresham JL, Rayner HC, et al. Nonadherence in hemodialysis: associations with mortality, hospitalization, and practice patterns in the DOPPS. Kidney Int. 2003;64(1):254-262.

14. Clark S, Farrington K, Chilcot J. Nonadherence in dialysis patients: prevalence, measurement, outcome, and psychological determinants Semin Dial. 2014;27(1):42-49.

15. Leggat JE. Pyyschosocial factors in patients with chronic kidney disease. Adherence with dialysis: a focus on mortality risk. Semin Dial. 2008;18(2):137-141.

16. Ibrahim S, Hossam M, Belal D. Study of non-compliance among chronic hemodialysis patients and its impact on patients' outcomes. Saudi J Kidney Dis Transpl. 2015;26(2):243-249.

17. Yu ZL, Yeoh LY, Seow YY, Luo XC, Griva K. Evaluation of adherence and depression among patients on peritoneal dialysis. Singapore Med J. 2012;53(7):474-480.

18. Weisbord SD, Mor MK, Sevick MA, et al. Associations of depressive symptoms and pain with dialysis adherence, health resource utilization, and mortality in patients receiving chronic hemodialysis. Clin J Am Soc Nephrol. 2014;9(9):1594-1602.

19. Afsar B, Akman B. Depression and nonadherence are closely related in dialysis patients. Kidney Int. 2009;76(6):679; response 679-680.

20. Alkatheri A, Alyousif S, Alshabanah N, et al. Medication adherence among adult patients on hemodialysis. Saudi J Kidney Dis Transpl. 2014;25(4):762-768.

21. Kalichman SC, Amaral CM, Swetzes C, et al. A simple single-item rating scale to measure medication adherence: further evidence for convergent validity. J Int Assoc Physicians AIDS Care (Chic). 2009;8(6): 367-374.

22. Sockalingam S, Blank D, Abdelhamid N, Abbey SE, Hirschfield GM. Identifying opportunities to improve management of autoimmune hepatitis: evaluation of drug adherence and psychosocial factors. $J$ Hepatol. 2012;57(6):1299-1304.

23. Finitsis DJ, Pellowski JA, Huedo-Medina TB, Fox MC, Kalichman SC. Visual analogue scale (VAS) measurement of antiretroviral adherence in people living with HIV (PLWH): a meta-analysis. J Behav Med. August 2016:1-13.
24. Zeller A, Ramseier E, Teagtmeyer A, Battegay E. Patients'self-reported adherence to cardiovascular medication using electronic monitors as comparators. Hypertens Res. 2008;31(11):2037-2043.

25. Gallagher BD, Muntner P, Moise N, Lin JJ, Kronish IM. Are two commonly used self-report questionnaires useful for identifying antihypertensive medication nonadherence? J Hypertens. 2015;33(5):1108-1113.

26. Becker S, Al Zaid K, Al Faris E. Screening for somatization and depression in Saudi Arabia: a validation study of the PHQ in primary care. Int J Psychiatry Med. 2002;32(3):271-283.

27. Kroenke K, Spitzer RL, Williams JB. The PHQ-9: validity of a brief depression severity measure. J Gen Intern Med. 2001;16(9):606-613.

28. Malasi TH, Mirza IA, el-Islam MF. Validation of the Hospital Anxiety and Depression Scale in Arab patients. Acta Psychiatr Scand. 1991;84(4):323-326.

29. Rahman TTA, El Gaafary MM. Montreal Cognitive Assessment Arabic version: reliability and validity prevalence of mild cognitive impairment among elderly attending geriatric clubs in Cairo. Geriatr Gerontol Int. 2009;9(1):54-61.

30. Lo C, Walsh A, Mikulincer M, Gagliese L, Zimmermann C, Rodin G. Measuring attachment security in patients with advanced cancer: psychometric properties of a modified and brief Experiences in Close Relationships scale. Psychooncology. 2009;18(5):490-499.

31. Hunter JJ, Maunder RG. Using attachment theory to understand illness behavior. Gen Hosp Psychiatry. 2001;23(4):177-182.

32. Mikulincer M, Shaver PR. Attachment in Adulthood: Structure, Dynamics, and Change. New York, NY: Guilford Press; 2007.

33. Stasiak CE, Bazan KS, Kuss RS, Schuinski AF, Baroni G. Prevalence of anxiety and depression and its comorbidities in patients with chronic kidney disease on hemodialysis and peritoneal dialysis. J Bras Nefrol. 2014;36(3):325-331.

34. Hedayati SS, Finkelstein FO, Kessler RC, et al. Epidemiology, diagnosis, and management of depression in patients with CKD. Am J Kidney Dis. 2009;54(4):741-752.

35. Feroze U, Martin D, Reina-Patton A, Kalantar-Zadeh K, Kopple JD. Mental health, depression, and anxiety in patients on maintenance dialysis. Iran J Kidney Dis. 2010;4(3):173-180.

36. McDade-Montez EA, Christensen AJ, Cvengros JA, Lawton WJ. The role of depression symptoms in dialysis withdrawal. Health Psychol. 2006;25(2):198-204. doi:10.1037/0278-6133.25.2.198.

37. Kalirao P, Pederson S, Foley RN, et al. Cognitive impairment in peritoneal dialysis patients. Am J Kidney Dis. 2011;57(4):612-620.

38. Murray AM, Pereira AA, Weiner DE, et al. Cognitive impairment in the aging dialysis and chronic kidney disease populations: an occult burden. Adv Chronic Kidney Dis. 2008;15(2):123-132.

39. Shea YF, Lam MF, Lee MSC, et al. Prevalence of cognitive impairment among peritoneal dialysis patients, impact on peritonitis and role of assisted dialysis. Perit Dial Int. 36(3):284-290. doi:10.3747/ pdi.2014.00247.

40. Pereira AA, Weiner DE, Scott T, Sarnak MJ. Cognitive function in dialysis patients. Am J Kidney Dis. 2005;45(3):448-462.

41. White RB. Adherence to the dialysis prescription: partnering with patients for improved outcomes. Nephrol Nurs J. 2004;31(4):432-435.

42. Kammerer J, Garry G, Hartigan M, Carter B, Erlich L. Adherence in patients on dialysis: strategies for success. Nephrol Nurs J. 2007;34(5):479-486. 
The International Journal of Nephrology and Renovascular Disease is an international, peer-reviewed open access journal focusing on the pathophysiology of the kidney and vascular supply. Epidemiology, screening, diagnosis, and treatment interventions are covered as well as basic science, biochemical and immunological studies. The manuscript management system is completely online and includes a very quick and fair peer-review system, which is all easy to use. Visit http://www. dovepress.com/testimonials.php to read real quotes from published authors.

Submit your manuscript here: https://www.dovepress.com/international-journal-of-nephrology-and-renovascular-disease-journal 